\title{
AN UNUSUAL CASE OF MITRAL VALVE CHORDAL RUPTURE
}

\author{
Rosa Lillo ${ }^{1}$, Gessica Ingrasciotta ${ }^{2}$, Gabriella Locorotondo ${ }^{1}$, Antonella Lombardo ${ }^{1}$, and \\ Francesca Graziani ${ }^{1}$ \\ ${ }^{1}$ Fondazione Policlinico Universitario Agostino Gemelli IRCCS \\ ${ }^{2}$ Università Cattolica del Sacro Cuore Scuole di Specializzazione
}

September 24, 2021

\begin{abstract}
In this report, we present a rare case of severe mitral regurgitation due to isolated mitral valve chordal rupture without valve leaflet prolapse in a patient with Fabry cardiomyopathy. This finding could be due to subvalvular apparatus storage of glycosphingolipids rather than fibro-elastic deficiency, underlying how close cardiological follow-up of Fabry patients must be comprehensive and not only focused on left ventricular hypertrophy and arrhythmias. We feel that our finding could be of interest for the readership of your Journal.
\end{abstract}

\section{Hosted file}

AN UNUSUAL CASE OF MITRAL VALVE CHORDAL RUPTURE.docx available at https://authorea.com/users/ 435502/articles/538479-an-unusual-case-of-mitral-valve-chordal-rupture 


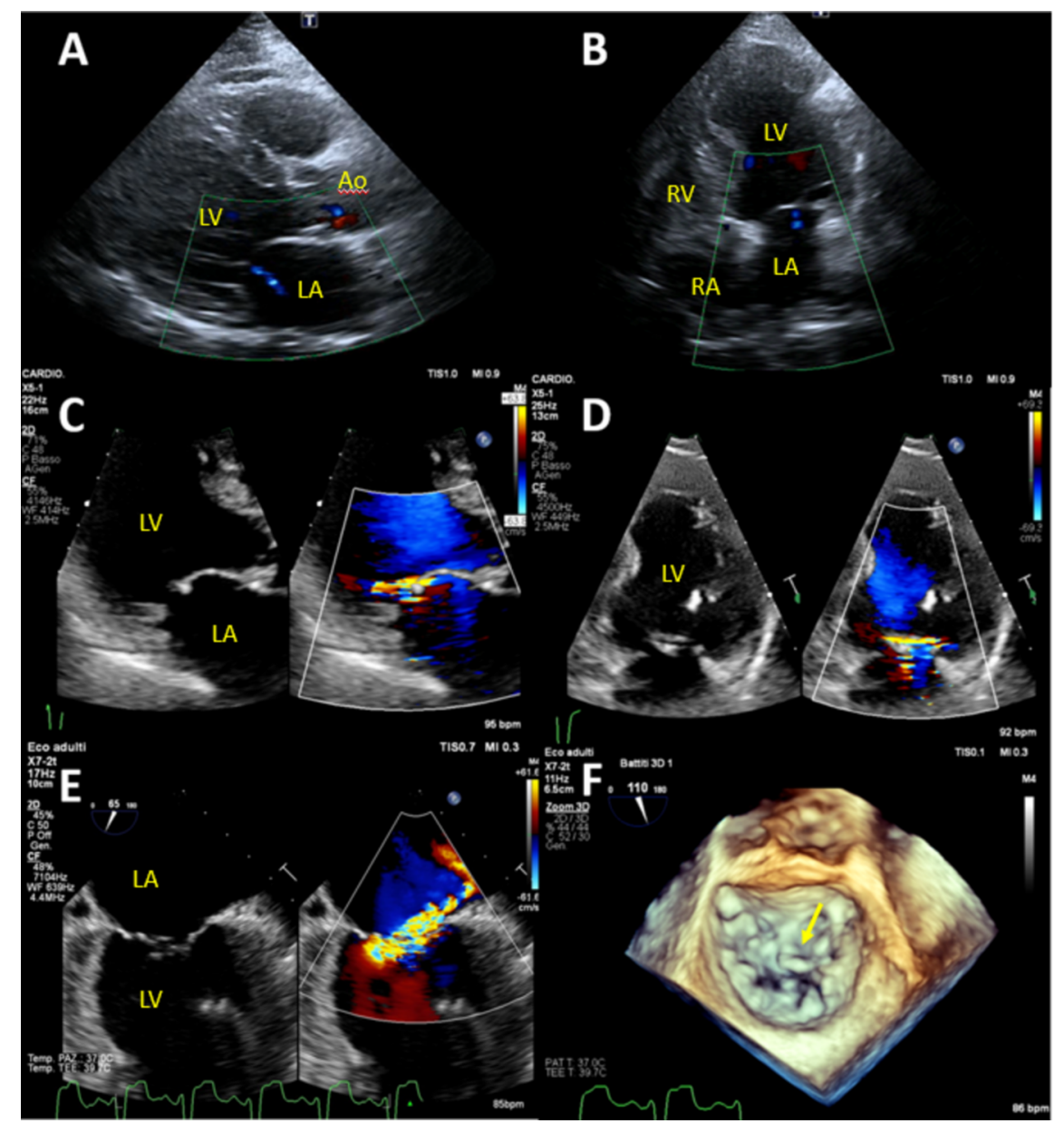

